REVISTA X, Curitiba, volume 14, n.6,p. 178-202, 2019.

\title{
A PESQUISA QUANTITATIVA NA SALA DE AULA DE ESPANHOL: A ANÁLISE DE UM ESTUDO
}

The Quantitative Research in the Spanish Classroom: the Analysis of a Study

\author{
Eduardo de Oliveira DUTRA (UNIPAMPA) ${ }^{1}$ \\ Gisele Benck de MORAES (UPF) ${ }^{2}$ \\ Marília dos Santos LIMA (UNISINOS) ${ }^{3}$
}

\begin{abstract}
RESUMO: O objetivo deste estudo é focalizar na investigação recente sobre o efeito e a durabilidade da intervenção instrucional na aprendizagem do presente do subjuntivo em orações temporais com cuando na língua espanhola como língua estrangeira. Pretendemos divulgar procedimentos específicos de pesquisa quantitativa na sala de aula de língua estrangeira e caracterizar o estudo sob análise tendo em vista questões metodológicas e conceitos relacionados à Instrução com Foco na Forma. Concluímos que o estudo quase-experimental (SPADA; LIGHTBOWN, 1997; DÖRNYEI, 2007) revisado apresentou intervenção instrucional explícita, isolada e baseada na produção. Além disso, observamos a estreita relação entre tipo de tarefa e conhecimento linguístico. Também pudemos verificar que o conceito de efeito duradouro é variável em função do tipo de dados que é submetido a tratamento estatístico.
\end{abstract}

PALAVRAS-CHAVE: Ensino e aprendizagem; Espanhol; Instrução com foco na forma.

\begin{abstract}
The purpose of this study is to focus on recent research on the effect and durability of instructional intervention in the learning of the present subjunctive in temporal clauses in which cuando is employed in Spanish as a foreign language. We intend to highlight specific procedures of quantitative research in the foreign language classroom and characterize the study under analysis in view of methodological issues and concepts related to Focus on Form Instruction. We conclude that the revised quasi-experimental study (SPADA; LIGHTBOWN, 1997; DÖRNYEI, 2007), presented explicit, isolated and production-based instructional intervention. In addition, we observe the close relationship between task type and linguistic knowledge. We have also observed that the concept of lasting effect varies according to the type of data that is subjected to statistical treatment.
\end{abstract}

KEYWORDS: Focus on form instruction; Spanish; Teaching and learning.

\footnotetext{
Doutor em Linguística Aplicada pela UNISINOS e Professor na UNIPAMPA. eduardodutra@unipampa.edu.br

${ }^{2}$ Doutora em Linguística Aplicada pela UNISINOS e Professora Titular do Curso de Letras da UPF. gbenck@upf.br

${ }_{3}^{3}$ Doutora em Linguística Aplicada pela University of Reading, no Reino Unido e Professora do PPG em Linguística Aplicada da UNISINOS. marilialim@unisinos.br
} 
REVISTA X, Curitiba, volume 14, n.6,p. 178-202, 2019.

\section{INTRODUÇÃO}

Pesquisas na área de aquisição de segunda língua (doravante ASL), focadas primordialmente na ocorrência de estruturas-alvo na língua dos aprendizes (LOOSE, 2006; ORTIZ-PREUSS, 2005; 2017; DUTRA, 2019a; 2019b), trataram do efeito e/ou da durabilidade de intervenções instrucionais que se destinaram ao ensino de formas linguísticas problemáticas ${ }^{4}$ a estudantes brasileiros dedicados à aprendizagem da língua espanhola.

Nesta investigação, analisamos um trabalho recente ${ }^{5}$ (MORAES; DUTRA; SIMIONI, 2018) sobre a aprendizagem do presente do subjuntivo do espanhol, em oração adverbial temporal com cuando, privilegiando a ocorrência das formas não esperadas. Portanto, não há qualquer pretensão de refletir principalmente a respeito dos dados referentes ao uso da estrutura alvo, com ou sem a especificação da sua ocorrência, por tipo de tarefa, devido a duas razões, a saber: (i) há um trabalho em processo de execução que está voltado à verificação da frequência da forma-alvo sob exame por modalidades de tarefa (para mais detalhes, ver Quadro 1) e (ii) o trabalho em revisão já reflete acerca da aplicação do presente do subjuntivo, em orações temporais, relacionada aos benefícios instrucionais.

A partir do exame da parte quantitativa referente à pesquisa supramencionada, pretendemos (1) incentivar discentes do curso de Letras e professores em serviço a desenvolver investigações quase-experimentais na sala de aula de língua estrangeira (doravante LE) e (2) apresentar, de maneira introdutória, procedimentos de investigação nessa linha. A opção por esse método de pesquisa ${ }^{6}$ encontra suporte no fato de que a investigação pode ser desenvolvida em uma única turma, a qual é submetida a uma

\footnotetext{
4 Por formas problemáticas, compreendemos estruturas linguísticas que, inclusive em níveis mais avançados, nas produções dos estudantes, do ponto de vista comunicativo, não revelam evidências de aprendizagem.

${ }^{5} \mathrm{O}$ estudo revisado é proveniente de uma pesquisa mais ampla (MORAES, 2014), na qual a pesquisadora verificou a aquisição do presente do subjuntivo em orações adverbiais com cuando, aunque e donde em produções orais e escritas de universitários. Nesse estudo, foram controladas cinco variáveis, a saber: etapa, tipo de prática, tipo de atividade, tipo de habilidade e tipo de conjunção, as quais apontaram índices oriundos de dados de aplicação do presente do subjuntivo do espanhol nas orações subordinadas adverbiais mencionadas. Ocorreram também formas alternativas (estruturas não esperadas) das quais provêm os dados referentes à não aplicação da forma-alvo. Nesse caso, Moraes (2014) evidencia questões de transferência, sem especificação dos índices alusivos aos tipos de formas alternativas, por tipo de conjunção, o que motivou uma análise mais detalhada da não aplicação do presente do subjuntivo em orações subordinadas temporais com cuando, através do estudo de Moraes, Dutra e Simioni (2018).

${ }^{6}$ Para a classificação de estudo quase-experimental como método de pesquisa, partimos de Paiva (2019). Quanto à indicação da existência de apenas um grupo de estudantes, em pesquisas quase-experimentais, tomamos como referência Larsen-Freeman e Long (2004).
} 
proposta de intervenção, sem necessidade de grupo de comparação. Em termos operacionais, isso pode permitir a execução de estudo na sala de aula de um(a) professor(a) colaborador(a) ou no próprio contexto de ensino do pesquisador. Dentre outros objetivos, apontamos o interesse em (3) discutir a relação entre conceitos da ASL e questões relacionadas a métodos de pesquisa, bem como (4) refletir a respeito da variabilidade conceitual da expressão efeito instrucional duradouro (grifo nosso). Para fins de organização do artigo, após a introdução, apresentamos a revisão da literatura. Por último, efetuamos a análise do estudo e tecemos as considerações finais.

\section{A INSTRUÇÃO COM FOCO NA FORMA: QUESTÕES CONCEITUAIS E METODOLÓGICAS}

$\mathrm{Na}$ área de aprendizagem de segunda língua (L2), a principal mudança nas últimas décadas ocorreu com a transição de um ensino tradicional, baseado em estruturas linguísticas, isto é, ensino com foco nas formas e cuja atenção estava dirigida explicitamente à gramática, à fonologia e ao vocabulário, para um ensino com ênfase à comunicação significativa (SPADA, 2014), sem atenção primordial para a forma ou correção do erro. Assim, buscando contrabalançar esses dois extremos, a Instrução com Foco na Forma (doravante IFF), inserida em um contexto comunicativo e significativo para o aluno, focaliza tanto a comunicação quanto a acuidade, incluindo atenção ao significado e à forma (SPADA, 1997; 2014).

De um lado, segundo Long (1991), a IFF consiste em chamar a atenção dos estudantes para elementos linguísticos que podem surgir incidentalmente em lições cujo foco primordial está no significado ou na comunicação. Já, por outro viés, Spada (1997, p. 73) define-a como

qualquer esforço pedagógico que é usado para chamar implícita ou explicitamente a atenção do aprendiz para a forma da língua-alvo. Isso pode incluir o ensino direto da língua (por exemplo, por meio de regras gramaticais) e/ou reações em relação aos erros dos aprendizes (por exemplo, feedback corretivo) ${ }^{7}$.

Salientamos que a definição de Spada (1997) é a adotada no presente estudo. A autora explica também que, na IFF, eventos pedagógicos ocorrem em abordagens baseadas no significado, em que o foco da atenção dos aprendizes a elementos

\footnotetext{
${ }^{7}$ Any pedagogical effort which is used to draw the learners' attention to language form either implicitly or explicitly. This can include the direct teaching of language (e. g. through grammatical rules) and/or reactions to learners' errors (e. g. corrective feedback).
} 
REVISTA X, Curitiba, volume 14, n.6,p. 178-202, 2019.

linguísticos ocorre espontaneamente ou de modo planejado, ao passo que a definição de Long restringe-se a eventos pedagógicos baseados no significado, em que a atenção dos estudantes a aspectos linguísticos sucede em resposta à percepção de necessidades comunicativas.

Para mais, cabe mencionar que a instrução explícita envolve o direcionamento da atenção dos aprendizes a aspectos da língua-alvo, por meio de explicações gramaticais ou do fornecimento de dados aos aprendizes, a fim de que prestem atenção a traços específicos para obterem generalizações metalinguísticas (NORRIS; ORTEGA, 2000). Por sua vez, na instrução implícita não há apresentação da regra, nem direcionamento da atenção dos aprendizes a formas particulares (NORRIS; ORTEGA, 2000).

Além do tipo de instrução, na ASL, há a investigação (SPADA et al., 2014) que privilegia o momento pedagógico da intervenção e a instrução baseada unicamente na habilidade linguística (para mais detalhes, ver ORTIZ-PREUSS, 2017). De um lado, segundo Spada e Lightbown (2008), existem duas abordagens relacionadas ao momento em que o professor deve efetuar a intervenção instrucional: separada ou integrada a práticas comunicativas, as quais remetem, respectivamente, à Instrução com Foco na Forma Isolada e à Instrução com Foco na Forma Integrada. Por outro, se o professor faz uso de tarefas no tratamento instrucional, a instrução pode ser baseada na compreensão ou na produção.

Já no que se refere ao estudo de síntese narrativa (SPADA, 1997), na ASL, dentre outros objetivos, ele tinha como propósito verificar se a instrução produzia diferença na aquisição da L2 e se havia um tipo de instrução (explícita e implícita) mais benéfico do que outro. Essa pesquisa envolveu a revisão de trinta pesquisas sobre a IFF, das quais treze eram investigações quase-experimentais, onze eram trabalhos experimentais e os demais pertenciam a outro tipo de estudo.

Quanto aos métodos de pesquisa, a diferenciação entre as pesquisas quaseexperimentais e experimentais pode ocorrer a partir de dois critérios, a saber: número de grupos e modalidade de distribuição dos participantes. Larsen-Freeman e Long (2004) explicam que estudos do primeiro tipo podem incluir apenas o grupo tratamento, uma vez que, durante a coleta de dados, a etapa anterior ao tratamento fornecido, correspondente aos dados provenientes dos pré-testes, pode servir como grupo controle. Além disso, nesse tipo de método, quanto aos procedimentos, a seleção dos 
REVISTA X, Curitiba, volume 14, n.6,p. 178-202, 2019.

participantes não é aleatória. Em contraste, investigações experimentais devem incluir pelo menos dois grupos (controle e experimental) e distribuir aleatoriamente os indivíduos por grupos (LARSEN-FREEMAN; LONG, 2004).

Paiva (2019), no capítulo de sua obra destinado aos métodos de pesquisa quantitativa, por exemplo, revisa e analisa um estudo que trata da aprendizagem de italiano por falantes nativos de inglês (SANTORO, 2012) e outro que versa sobre brasileiros que estudam italiano (SOUZA, 2009) a fim de identificar as características, respectivamente, dos métodos experimentais e quase-experimentais. Para a consecução de tal propósito, a autora define e caracteriza esses tipos de métodos e, posteriormente, apresenta aspectos de cada investigação, tais como: objetivo, participantes, grupo de pesquisa e grupo controle, hipótese, variável independente, variável dependente, medição, causa e efeito.

Contudo, em função dos propósitos deste trabalho elencados [de (1) a (4)], focamos nos testes, correlacionando-os com os conhecimentos explícito e implícito, na intervenção pedagógica, caracterizando-a, e na variabilidade conceitual do termo efeito instrucional durável, apresentando o comportamento da (não) estrutura alvo ao longo da coleta. Assim, na seção destinada à análise do trabalho de Moraes, Dutra e Simioni (2018), além de tratarmos de questões sobre procedimentos e instrumentos de pesquisa, refletiremos a respeito da metodologia de intervenção.

Nos últimos anos, os temas das investigações sobre a IFF envolveram os tipos de instrução em questões de pesquisa relacionadas aos seguintes tópicos: efeito e durabilidade, forma-alvo como conhecimento(s) linguístico(s), momento de instrução (Instrução Isolada ou Instrução Integrada), prontidão de desenvolvimento dos aprendizes, grau de complexidade $\mathrm{da}(\mathrm{s})$ forma(s) meta, redução de transferência linguística e instrução baseada na produção ou na compreensão, entre outros interesses de pesquisa.

No contexto brasileiro, os estudos que tratam da instrução explícita e/ou implícita e o primeiro eixo temático supracitado são os mais frequentes ${ }^{8}$. Logo, há necessidade de mais investigações que abranjam os demais eixos temáticos. Contudo, cabe destacar que, independente das questões de investigação, é relevante que se defina o objeto linguístico de instrução. Afinal, a palavra forma envolve aspectos da pragmática, gramática, léxico e fonologia referentes à linguagem (ELLIS, 2001). Então,

\footnotetext{
${ }^{8}$ Aqui, efeito e durabilidade devem ser compreendidos a partir de dados de aplicação da forma-alvo.
} 
as estruturas que são alvo de instrução podem fazer parte de tratamento instrucional, por meio de seleção prévia ou momentânea (durante o ato comunicativo), dependendo do modo de instrução, o qual pode ser predeterminado e/ou não planejado.

Entretanto, a partir de um conjunto de traços da L2, é necessário que o professor e/ou pesquisador delimite a forma linguística que integrará o tratamento instrucional. Essa seleção pode se basear em critérios como estudos na ASL, lista de conteúdos linguísticos do programa de ensino, experiência do professor de LE, situação atual de ensino e aprendizagem, solicitação por parte do grupo de alunos etc. Já no tocante aos tipos de dados (formas (não) esperadas) que são utilizados, para fins de tratamento estatístico, nas pesquisas sobre a IFF no país, observemos o seguinte:

Há menos registro de investigações (LOOSE, 2006; DUTRA, 2015) que trataram dos benefícios do tratamento instrucional, em curto e em médio ou longo prazos, com base em índices de aplicação das formas metas e simultaneamente na sua não produtividade, do que pesquisas a respeito da IFF que trataram dos efeitos da durabilidade da intervenção pedagógica, baseadas, primordialmente, na análise e discussão de dados provenientes de aplicação da(s) forma(s)-alvo (MORAES; DUTRA; SIMIONI, 2018, p. 468).

Portanto, notamos que os estudos a respeito da IFF, no contexto brasileiro, estão centrados, predominantemente, ao longo das etapas posteriores à intervenção pedagógica, em dados relacionados ao aumento de frequência das estruturas meta. Nesse sentido, é possível verificarmos se a intervenção pedagógica administrada promoveu o aumento de aplicação e/ou de identificação ${ }^{9}$ do objeto linguístico de instrução, em curto, em médio ou em longo prazo. Por conseguinte, os dados provenientes da não aplicação da(s) estrutura(s)-alvo, correspondentes aos erros, tendem a ser utilizados, em menor proporção, para fins de análise, se comparados aos dados correspondentes à sua ocorrência.

A opção pelo manuseio de dados correspondentes à ocorrência de formas não esperadas, por parte do pesquisador, poderá trazer benefícios, de cunho qualitativo e/ou quantitativo, para seu estudo. Dito de outra maneira, se o pesquisador explorar os dados correspondentes aos erros, referentes à(s) estrutura(s) meta, além da sua categorização, ao longo das etapas de coleta de dados, poderá ser possível a mensuração do comportamento (queda, estabilidade e/ou avanço) de cada tipo de erro, em termos de

\footnotetext{
${ }^{9}$ Assumimos como teste de identificação aquele que requer apenas compreensão, portanto, com ausência de produção.
} 
REVISTA X, Curitiba, volume 14, n.6,p. 178-202, 2019.

frequência, na língua dos aprendizes. Essa escolha metodológica pode ser útil para uma discussão acerca da constituição do sistema interlinguístico, em direção à língua-alvo, e a respeito do papel da intervenção instrucional nesse processo.

Por último, se os dados submetidos a tratamento estatístico forem aqueles correspondentes à ocorrência da(s) forma(s) meta, o exame dos efeitos instrucionais, em relação à sua aprendizagem, estará associado ao aumento de sua frequência, em curto prazo, tornando-se produto da diferença entre os índices oriundos do(s) pós-teste(s) imediato(s) e do(s) pré-teste(s). Em comparação, a durabilidade dos benefícios instrucionais envolverá a estabilidade do aumento da frequência da estrutura meta, que foi obtida no pós-teste imediato e mantida no pós-teste postergado.

Se partirmos de dados alusivos à não ocorrência da(s) forma(s) meta, a expressão efeito instrucional durável (grifo nosso) refere-se, simultaneamente, em curto prazo, à redução das suas respectivas formas alternativas e, em médio ou longo prazo, à sua estabilidade. Essa relação entre os tipos de dados, referentes à (não) frequência da(s) estrutura(s) meta, e o efeito e/ou a durabilidade ${ }^{10}$ dos benefícios instrucionais ficarão evidentes mais adiante no estudo sob revisão.

Na ASL, cabe assinalarmos a relevância do instrumento de coleta de dados, visto que ele pode ser empregado para mensurar o conhecimento da língua-alvo. A literatura sobre a IFF (NORRIS; ORTEGA, 2000) tem apontado para a necessidade de estudos que incluam, em suas metodologias, maior número de instrumentos de obtenção de dados que privilegiem o uso espontâneo da língua-alvo. Destacamos, quanto ao conhecimento implícito, que o desenho de seu respectivo instrumento de medida pode comprometer o número de dados, em função de sua natureza livre. E, também, há questionamentos a respeito da validade de testes como instrumentos destinados à mensuração de conhecimento linguístico (SPADA; TOMITA, 2010).

Norris e Ortega (2000), a partir de um conjunto de testes, categorizaram os seus resultados em quatro tipos: julgamento metalinguístico, resposta selecionada, resposta construída de modo restrito e resposta elaborada de maneira livre. Segundo esses autores, as três primeiras categorias podem ser compreendidas como tarefas de resultados controlados, já a última classe diz respeito a medidas referentes ao uso espontâneo da L2.

\footnotetext{
${ }^{10}$ A discussão da questão sobre o conceito de efeito e durabilidade, com base em dados de (não) aplicação das estruturas-alvo, esteve baseada na pesquisa de DUTRA (2015).
} 
REVISTA X, Curitiba, volume 14, n.6,p. 178-202, 2019.

Quanto às definições de tarefas, como medidas de conhecimento linguístico, Moraes (2016) afirma que atividades ${ }^{11}$ controladas remetem a todas as tarefas que permitem o monitoramento de sua execução, ou seja, por meio de questões preestabelecidas, enquanto que, nas atividades livres, os aprendizes têm total autonomia em sua execução, com ausência de controle quanto ao número de questões e ao uso da regra-alvo. De acordo com Moraes (2016), atividades controladas e livres aludem, respectivamente, ao conhecimento explícito e implícito.

Conforme Ellis (1997), o conhecimento explícito é analisável e envolve metalinguagem. Para esse autor, conhecimento analisável refere-se ao saber sobre itens da L2 e suas estruturas, das quais o aprendiz é consciente, ao passo que "metalinguagem" alude à linguagem para analisar ou descrever a língua-alvo (RICHARDS; PLATT; WEBER, 1985). Contudo, Ellis (1997) ressalta que o conhecimento analisável pode existir independentemente do uso de metalinguagem, visto que é possível a verbalização da regra linguística por meio de linguagem não técnica.

No que tange ao uso controlado ou espontâneo, respectivamente do conhecimento explícito ou implícito, Ellis (2005) explica que é possível acessar esse conhecimento em situações livres, isto é, de uso espontâneo da L2. Em contraste, aquele pode ser acessado de maneira controlada. Bialystok (1982) afirma que esses dois tipos de conhecimento variam segundo a demanda da tarefa em termos de análise e de controle. Para essa autora, por exemplo, tarefas escritas que propõem a identificação e a correção de erro [+ analisada, - automática] servem como medidas de conhecimento linguístico de natureza controlada. Na sequência, tratamos do estudo que originou nossa análise.

\section{O ESTUDO SOB ANÁLISE}

Moraes, Dutra e Simioni (2018) investigaram o papel da intervenção instrucional sobre a redução de estruturas referentes a não aplicação do presente do subjuntivo do espanhol, ao longo das etapas pós-instrucionais, em orações subordinadas temporais com cuando, no caso de Cuando pueda, viajaré. Os pesquisadores apontaram a dificuldade de seus alunos, em nível de graduação, no que concerne ao processo de aquisição dessa forma. Houve também menção à menor quantidade de estudos, no

\footnotetext{
${ }^{11}$ Atividades e tarefas são compreendidas indistintamente no presente estudo.
} 
REVISTA X, Curitiba, volume 14, n.6,p. 178-202, 2019.

contexto brasileiro, que controlaram concomitantemente dados alusivos à (não) ocorrência das formas linguísticas esperadas.

Integraram a pesquisa doze estudantes, de determinado curso de Letras de uma instituição privada. A obtenção dos dados ocorreu em três etapas, a saber: (a) antes da intervenção pedagógica (pré-teste); (b) imediatamente após o tratamento instrucional (pós-teste imediato); e (c) após a intervenção, com maior intervalo entre a sua administração e a última coleta (pós-teste postergado). Os dados das etapas (b) e (c) foram obtidos, respectivamente, uma e sete semanas após o tratamento instrucional, por meio de tarefas de perguntas controladas, descrição de imagens e criação de história (produção oral), preenchimento de lacunas, e descrição de imagens e criação de história (produção escrita), salientamos que, para tratamento dos dados, foi utilizado o Teste Normal Padrão ${ }^{12}$. Para fins de ilustração, apresentamos um exemplo de cada tipo de tarefa nos Apêndices deste estudo.

Quanto ao tratamento instrucional, houve instrução explícita sobre os modos indicativo e subjuntivo, assim como a respeito da tarefa de produção. Além disso, em um segundo momento, ocorreu um estudo contrastivo entre o presente do subjuntivo e o futuro do subjuntivo. Houve também a realização de tarefas de preenchimento de lacunas e respostas orais a perguntas. Por último, foram propostas tarefas de produções orais e escritas.

A análise dos resultados sucedeu, primeiramente, por meio de apresentação de casos de erros, referentes ao presente do subjuntivo, em orações subordinadas temporais com cuando. Posteriormente, houve a análise dos resultados, oriundos de dados de não aplicação dessa forma-meta e de dados correspondentes à sua ocorrência. Os resultados apontaram formas alternativas, tais como: mudança de código, como em Cuando estiver en Barcelona (Cuando esté en Barcelona); substituição gramatical, no caso de Cuando volver a viajar (Cuando vuelva a viajar); erro de conjugação verbal, sucedido em Cuando saiba/supa la noticia (Cuando sepa la noticia); e uso inadequado de tempo e modo $^{13}$, ocorrido em Cuando mi hermano compró la chaqueta (Cuando mi hermano compre la chaqueta).

\footnotetext{
${ }^{12}$ Este teste permite a verificação de duas hipóteses: a hipótese nula, segundo a qual há igualdade nas proporções, e a hipótese de acordo com a qual as proporções são diferentes. Em um nível de significância de $5 \%$, a confirmação da hipótese nula é registrada com um resultado de Z entre $-1,96$ e 1,96. Os resultados de $\mathrm{Z}$ que estiverem fora deste intervalo permitem a rejeição da hipótese nula e, consequentemente, a confirmação de que há uma diferença significativa entre as proporções (MORAES; DUTRA; SIMIONI, 2018).

${ }^{13}$ Optamos por esta classificação, visto que os autores não trazem uma nomenclatura específica.
} 
REVISTA X, Curitiba, volume 14, n.6,p. 178-202, 2019.

No que tange aos índices de não aplicação do presente do subjuntivo (formas não esperadas), em oração subordinada temporal com cuando, a frequência dos erros do pré-teste, em comparação ao pós-teste imediato, reduziu em curto prazo, e se manteve praticamente estável, no pós-teste postergado, em médio prazo. O efeito da IFF sobre os erros foi corroborado pelo Teste Normal Padrão $(Z=15,92)$. Em comparação, a diminuição do uso de erros do pós-teste imediato em relação ao pós-teste postergado não se mostrou relevante estatisticamente $(Z=0,56)$. No que concerne à frequência do presente do subjuntivo em orações subordinadas temporais com cuando, houve, em curto prazo, aumento ascendente dessa forma, que se estabiliza em médio prazo.

Os pesquisadores Moraes, Dutra e Simioni (2018) concluíram que a administração da intervenção pedagógica produziu efeito durável sobre os erros. Além disso, apontaram a existência de transferência do Português do Brasil (PB) no processo de aprendizagem da forma-meta. Também, os autores sugeriram a possibilidade de utilização dos dados referentes às formas alternativas (não aplicação) para fins de indicação dos efeitos favoráveis do tratamento adotado.

\section{CARACTERIZAÇÃO DO ESTUDO SOB EXAME}

Nossa análise dos dados parte do estudo supramencionado e tem em vista as seguintes categorias: escolha do objeto de estudo, método de investigação, tipo de dados, efeito e durabilidade, tratamento instrucional, instrumento de coleta de dados e conhecimento linguístico.

Assinalamos, também, que a seleção do objeto de instrução tem respaldo na experiência dos pesquisadores como professores, conforme foi apontado na introdução de seu estudo, visto que, em seus contextos de ensino, o presente do subjuntivo, em oração adverbial temporal com cuando, parece ser uma estrutura problemática, tendência que encontra suporte na literatura da ASL (BOÉSSIO, 2003). Logo, a opção pelo objeto de instrução possui relação com os erros frequentes que parecem emergir na sala de aula durante as produções de estudantes.

Em relação ao método de investigação, podemos observar que as participantes eram alunas de um curso de Letras. Essa informação, inicialmente, não nos permite afirmar se elas eram oriundas de uma ou de duas turmas. Portanto, com o objetivo de obtermos mais detalhes sobre as estudantes, recorremos a um estudo mais amplo (MORAES, 2014), o qual indicou que as participantes pertenciam a uma turma correspondente ao sexto semestre da disciplina de espanhol. Posto isso, ao partirmos 
REVISTA X, Curitiba, volume 14, n.6,p. 178-202, 2019.

dos critérios estabelecidos por Larsen-Freeman e Long (2004), justificamos a caracterização do estudo revisado como quase-experimental pelo fato de haver apenas um grupo, o qual foi submetido a tratamento instrucional. Por conseguinte, não houve grupo controle.

A afirmação de que os dados alusivos à frequência do presente do subjuntivo do espanhol, em oração adverbial temporal com cuando, nos estudos sobre a IFF, no contexto brasileiro, são os mais explorados é o que parece sustentar a decisão metodológica pelo controle simultâneo da (não) ocorrência da forma-alvo na pesquisa de Moraes, Dutra e Simioni (2018).

A tomada de decisão, nessa linha, traz implicações interpretativas. O estudo sob análise verificou se houve efeitos duráveis (objetivo 1) e a existência de casos de transferência (objetivo 2). No que tange ao objetivo 1, a interpretação dependerá se os dados analisados remetem unicamente aos erros (caso 1) e/ou se aludem às formas esperadas (caso 2). No caso 1 , o conceito de efeito remete à diminuição dos erros do pré-teste, em comparação ao pós-teste imediato, conforme observamos no Gráfico 1:

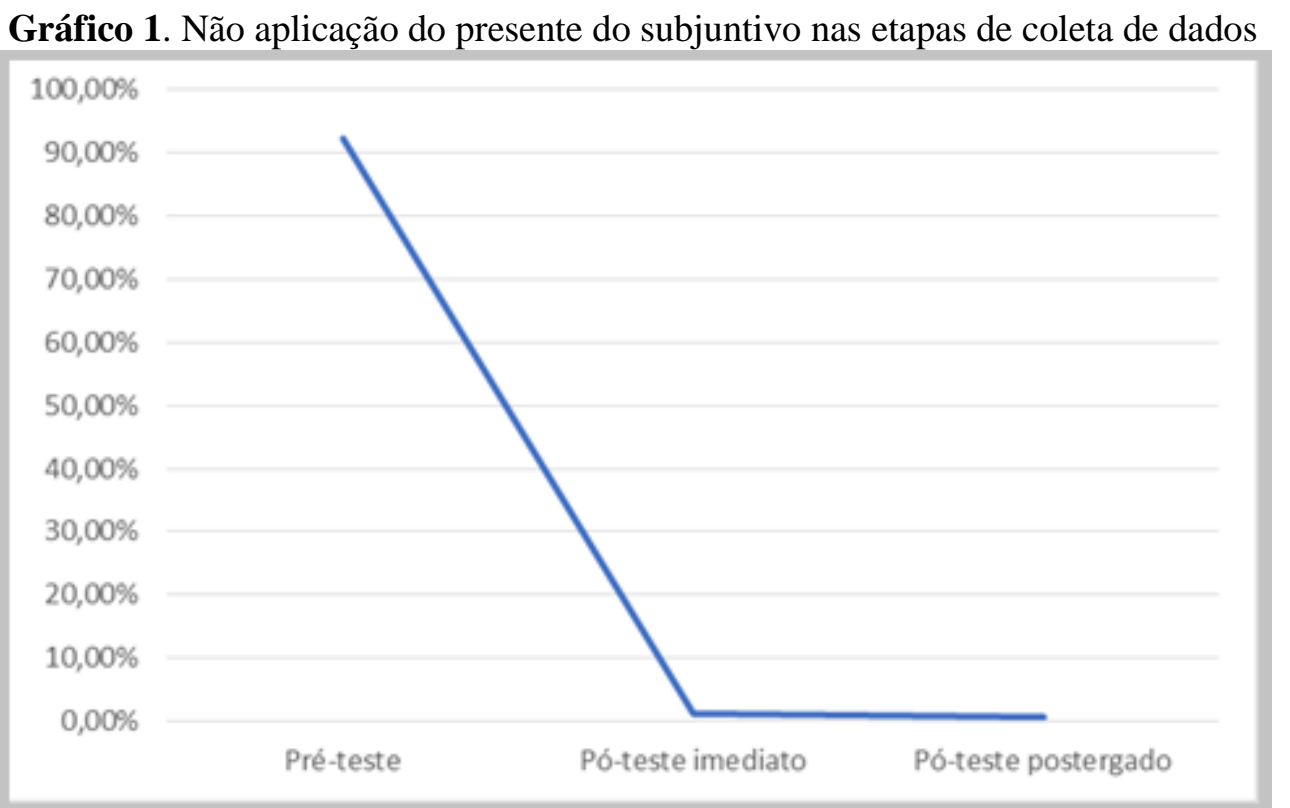

Fonte: Moraes, Dutra e Simioni (2018).

A partir do Gráfico 1 é possível constatarmos uma queda expressiva dos índices de formas não esperadas, as quais foram empregadas, no lugar do presente do subjuntivo do espanhol, em contexto de oração subordinada com cuando, entre o préteste e o primeiro pós-teste, o que foi representado por uma linha descendente. Por sua vez, a diferença de aplicação dos erros entre os dois pós-testes foi demonstrada por 
REVISTA X, Curitiba, volume 14, n.6,p. 178-202, 2019.

meio de uma linha estável, o que sugere, em médio prazo, a manutenção do comportamento indicado dessas formas alternativas em curto prazo. Logo, do ponto de vista estatístico e aquisicional, o manuseio de dados de não aplicação da estrutura-alvo, para fins de análise, permite a observância de efeitos duradouros, por meio da redução dos seus erros no pós-teste imediato (curto prazo), acompanhado de seu comportamento estável no pós-teste postergado (médio prazo).

Em comparação, no caso 2, a verificação do efeito e da durabilidade de intervenção instrucional, com base em dados oriundos unicamente de formas esperadas, aponta para o seu aumento de frequência e a estabilidade desse comportamento, ao longo das etapas de coleta de dados, nas produções linguísticas das participantes, conforme constatamos no Gráfico 2:

Gráfico 2. Aplicação do presente do subjuntivo nas etapas de coleta de dados

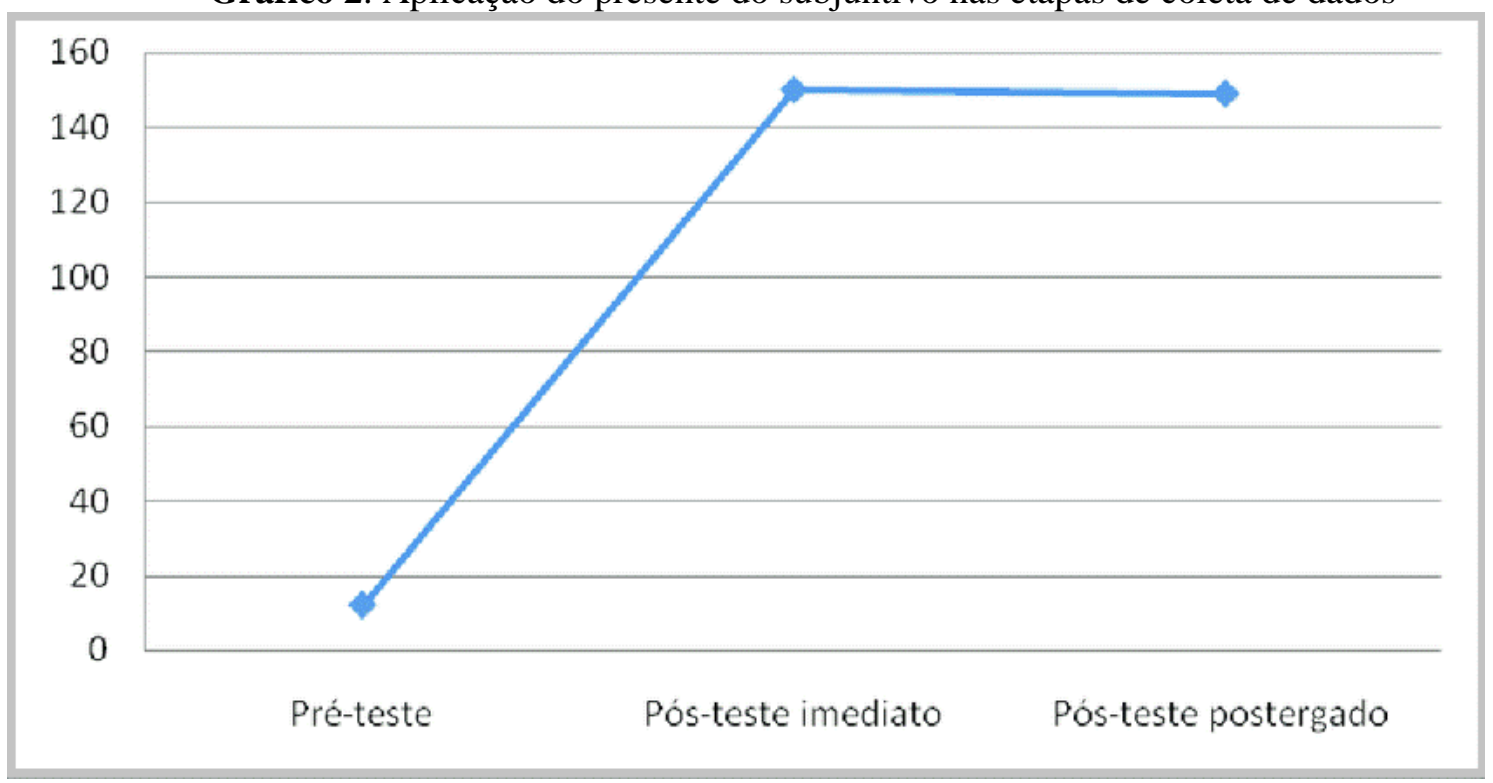

Fonte: Moraes, Dutra e Simioni (2018).

Assim, com base no Gráfico 2, podemos indicar o aumento de frequência do presente do subjuntivo do espanhol, em curto prazo, seguido praticamente da sua estabilidade, em termos de incidência, em médio prazo. Portanto, o uso de dados provenientes da estrutura-alvo, para fins de análise, permite o apontamento de efeitos duráveis, com base no aumento da forma esperada, no pós-teste imediato (curto prazo), o qual é acompanhado de seu comportamento estável no pós-teste postergado (médio prazo). Isso significa uma relação inversamente proporcional entre formas (não) esperadas, isto é, à medida que os erros diminuíram e se estabilizaram entre as 
REVISTA X, Curitiba, volume 14, n.6,p. 178-202, 2019.

participantes, a forma meta aumentou sua frequência e apresentou comportamento estável nas etapas posteriores à intervenção pedagógica.

No que diz respeito ao objetivo (2), durante o estudo revisado, há o apontamento de categorias de erros que podem ser divididas em dois grupos: caso de transferência e formas alternativas. Essas categorizações nos permitem afirmar o seguinte: a transferência integra o grupo de formas não esperadas e nem toda forma alternativa é evidência de transferência, visto que pode emergir como hipótese de regras internas da própria língua do aprendiz, como no caso de erro de conjugação verbal, apontado anteriormente.

Cabe assinalarmos que não era o objetivo dos autores (MORAES; DUTRA; SIMIONI, 2018) do estudo sob análise a indicação particular das formas alternativas, referentes ao presente do subjuntivo, em oração adverbial temporal com cuando, ao longo das etapas de coleta de dados, uma vez que o foco estava centrado unicamente na sua categorização. Contudo, ressaltamos que, caso se realizasse o procedimento metodológico nessa linha, haveria a possibilidade de verificar que tipos de formas alternativas, como no caso de Cuando yo entrar, hablaré contigo (Cuando yo entre, hablaré contigo), foram mais ou menos sensíveis ao tratamento instrucional adotado.

Já a fim de tratarmos da questão sobre a relação entre os instrumentos de coleta de dados e os tipos de conhecimento da língua-alvo, partimos novamente do estudo ${ }^{14}$ do qual foram provenientes os dados do artigo sob análise. Na sequência, através do Quadro 1, apresentamos a classificação de Moraes (2014), pois pretendemos indicar a que tipo de conhecimento se refere cada tarefa, o que, em estudo futuro, possibilitará a verificação de sua validade e confiabilidade como medidas de conhecimento linguístico.

Quadro 1. Tarefas orais e escritas

\begin{tabular}{|l|c|c|c|}
\hline \multicolumn{1}{|c|}{ Tipo de Tarefas } & Produção oral & Produção escrita & Tipo de conhecimento \\
\hline (1) Preenchimento de lacuna & & $\mathrm{X}$ & Conhecimento explícito \\
\hline (2) Múltipla escolha & & $\mathrm{X}$ & Conhecimento explícito \\
\hline (3) Descrição de imagem & $\mathrm{X}$ & $\mathrm{X}$ & $\begin{array}{c}\text { Conhecimento } \\
\text { explícito/implícito }\end{array}$ \\
\hline (4) Criação de história & $\mathrm{X}$ & $\mathrm{X}$ & $\begin{array}{c}\text { Conhecimento } \\
\text { explícito/implícito }\end{array}$ \\
\hline (5) Perguntas controladas & $\mathrm{X}$ & & Conhecimento explícito \\
\hline
\end{tabular}

Fonte: Adaptado de Moraes (2014).

A partir do Quadro 1, podemos observar que as tarefas foram centradas na produção das participantes e que se optou por um menor número de tarefas de produção

\footnotetext{
${ }^{14}$ Uma reanálise dos dados, para este propósito, está em processo de desenvolvimento.
} 
REVISTA X, Curitiba, volume 14, n.6,p. 178-202, 2019.

oral. Além disso, constatamos que houve duas modalidades de tarefas que privilegiaram, concomitantemente, mas em separado, as habilidades de produção e os conhecimentos explícito e implícito. Já as atividades restantes, além de integrarem ambas as habilidades mencionadas, foram consideradas prováveis tarefas de conhecimento explícito da língua-alvo.

As tarefas propostas tiveram como referência Norris e Ortega (2000), que agruparam os instrumentos dos estudos que compõem a sua meta-análise como pertencentes a respostas fechadas ou abertas (ELLIS, 2005). Posto isso, conforme já mencionamos, sublinhamos que as tarefas (3) e (4), referentes aos Apêndices C e D, ora integram a categoria de respostas fechadas, ora remetem à classe de respostas abertas, em virtude de a criação de histórias e a descrição de imagens poderem ser de natureza livre ou controlada, a depender do desenho da tarefa. Por sua vez, as tarefas (1), (2) e (5), que correspondem, respectivamente, aos Apêndices A, B e E, estabelecem previamente o número de formas linguísticas a serem produzidas. A opção por tarefas de resposta fechada, no desenho de pesquisa, garante um número de dados, para tratamento estatístico, em maior proporção do que tarefas de respostas abertas. Consequentemente, a não ser que o propósito da investigação esteja dirigido unicamente para verificação da interação entre o tipo de instrução e a forma meta como modalidade de conhecimento explícito, pode haver prejuízos investigativos.

Vale mencionar que, conforme já apontado, há lacunas no que tange à necessidade de investigações sobre a IFF que incluam maior número de medidas de conhecimento implícito (NORRIS; ORTEGA, 2000). Talvez o melhor caminho seja a inclusão de ambas as medidas de conhecimento linguístico, na metodologia de trabalhos sobre a IFF, e com maior número de tarefas que propicie o uso espontâneo da línguaalvo, visto que, em decorrência de sua natureza livre, o desenho de tarefas referente a esse tipo de conhecimento pode comprometer o número de dados.

Quanto à última unidade de análise, verificamos que o tratamento instrucional adotado no estudo sob exame abrangeu uma série de estratégias pedagógicas, as quais são sumarizadas do seguinte modo: instrução explícita; instrução baseada na produção; instrução com foco na forma isolada e estudo contrastivo entre língua materna e línguaalvo. No estudo sob análise, as explicações sobre os modos indicativo/subjuntivo, em sua amplitude e partindo de exemplos, aponta para uma didática dedutiva. Conforme já assinalamos, comentários sobre o funcionamento de estruturas, o que requer, muitas 
REVISTA X, Curitiba, volume 14, n.6,p. 178-202, 2019.

vezes, o uso de metalinguagem, fazem parte de ações pedagógicas, de natureza explícita, que estão destinadas ao direcionamento da atenção dos aprendizes para aspectos particulares do insumo recebido.

Assim, no estudo revisado, a instrução explícita parece ter ocorrido em etapa anterior a atividades, cujas práticas eram controladas ou livres, isto é, houve preparação prévia das aprendizes para a execução de tarefas de produção. Essas ações pedagógicas caracterizam a instrução adotada como de natureza explícita e isolada. Para além, destacamos que a Instrução com Foco na Forma Isolada pode envolver feedback explícito, terminologia metalinguística, declarações da regra e explicações (SPADA; LIGHTBOWN, 2008). Portanto, a opção pedagógica pela adoção de intervenção separada de atividades comunicativas pode encontrar respaldo no fator influência da L1. Além disso, segundo Spada e Lightbown (2008), a Instrução com Foco na Forma Isolada pode ser usada quando a L1 exerce forte influência sob formas da L2. Com base no exame do estudo que originou este trabalho, notamos que os autores, na introdução, apresentaram evidências de influência da L1 em direção à L2, como produto de sua observação de sala de aula, como no caso ${ }^{15}$ de Cuando viajares, comprarás muchos regalos. De acordo com os pesquisadores, existe uma tendência de emprego do que corresponde, em PB, ao futuro do subjuntivo na oração subordinada.

Por último, mas não menos importante, é possível observarmos que a habilidade predominante nas tarefas é a produção em ambas as modalidades. Consequentemente, a instrução baseada na produção pode contribuir para a aquisição. Dado que, durante a produção, os aprendizes, por exemplo, podem perceber problemas linguísticos e lacunas entre a sua língua e a língua-alvo (SWAN, 1995; 1998). No estudo sob análise, as participantes, no decurso das atividades de produção, tiveram oportunidades de perceber que o seu conhecimento linguístico era insuficiente para comunicar-se na língua-alvo. A partir do exposto, fica evidente que a intervenção instrucional, presente no trabalho de Moraes, Dutra e Simioni (2018), é produto de um conjunto de estratégias pedagógicas destinadas ao ensino do presente do subjuntivo do espanhol, em orações temporais com cuando.

\section{CONSIDERAÇÕES FINAIS}

\footnotetext{
${ }^{15}$ Exemplo proveniente do estudo revisado.
} 
REVISTA X, Curitiba, volume 14, n.6,p. 178-202, 2019.

Através da análise proposta no presente artigo, buscamos divulgar os procedimentos específicos de pesquisa quantitativa na sala de aula de língua estrangeira e caracterizar a pesquisa que originou o presente trabalho partindo de questões metodológicas e conceitos relacionados à IFF.

No estudo analisado, observamos que a intervenção instrucional era de natureza explícita, planejada e isolada. Somado a isso, pudemos constatar um método de pesquisa quase-experimental, que abrangeu três etapas de coleta de dados, cujos instrumentos de obtenção de dados representaram medidas de conhecimento explícito e implícito, as quais estavam centradas na habilidade de produção em ambas as modalidades (instrução baseada na produção).

No que tange ao tipo de instrução, ao momento pedagógico, à habilidade comunicativa e à seleção do objeto de instrução, foi possível observarmos que houve as explicações de regra e o uso de informações metalinguísticas, mas ambas ocorreram separadamente das atividades controladas e livres. Na realidade, a instrução explícita serviu como preparação para tais tarefas que focaram na produção das alunas, as quais tiveram oportunidade de participar de maior número de atividades dirigidas à produção escrita. Além disso, constatamos que o objeto de instrução resultou de uma escolha baseada na experiência profissional dos pesquisadores.

Quanto ao papel do tratamento, verificamos que, metodologicamente, a decisão pela submissão de dados de (não) aplicação da forma esperada a tratamento estatístico traz implicações conceituais e interpretativas. Nesse sentido, a interpretação de efeito durável, oriunda de formas alternativas (não aplicação) sugere que a intervenção pedagógica promoveu, em curto prazo, a redução dos erros, que se mantiveram estáveis em médio prazo. Em um sentido inverso, a exploração de dados provenientes da frequência da forma-meta (presente do subjuntivo, no contexto de oração adverbial temporal com cuando), ao longo das etapas, permite compreender efeito durável como aumento do objeto de instrução, no pós-teste imediato, e que permanece estável, em termos de frequência, no pós-teste postergado.

Já no que diz respeito à relação entre o tipo de instrumento de coleta de dados e a modalidade de conhecimento linguístico, ainda que no estudo revisado não houve interesse em explorar a interação entre a intervenção pedagógica adotada para o ensino da forma-alvo e o tipo de conhecimento provável de ser adquirido, foi possível constatarmos a existência de tarefas (descrição de imagem e criação de história) que se 
REVISTA X, Curitiba, volume 14, n.6,p. 178-202, 2019.

diferenciaram apenas em função de sua natureza controlada ou livre, resultando, portanto, separadamente, em medidas de conhecimento explícito e conhecimento implícito. Ressaltamos o fato de as alunas terem participado de tarefas que representaram unicamente medidas de conhecimento explícito.

Por fim, esperamos que discentes e professores em serviço de línguas estrangeiras se ocupem de pesquisas quantitativas de caráter intervencionista. No caso de optarem por estudos sobre a IFF, pode ser possível o estabelecimento do objeto de instrução por meio de critérios baseados em questões da ASL e de sala de aula. Nessa linha, é necessário também que haja a definição da intervenção instrucional, do número de etapas de coleta de dados e dos instrumentos de obtenção de dados tendo em vista habilidades comunicativas e conhecimento linguístico, isto é, tarefas de produção e/ou compreensão como medidas de uso monitorado e espontâneo da língua-alvo para a obtenção de dados com fins estatísticos. Cabe assinalarmos que a indicação de futuros estudos sobre a IFF relacionados ao tipo de conhecimento linguístico, à habilidade linguística e à redução de transferência é apenas um caminho, visto que, conforme já apontamos anteriormente, há escassez de estudos a respeito de outros eixos temáticos.

\section{REFERÊNCIAS}

BOÉSSIO, C. A transferência indevida do infinitivo flexionado no ensino do espanhol para brasileiros. 96f. Dissertação (Mestrado em Letras) - Escola de Educação, Universidade Católica de Pelotas, Pelotas, 2003.

DÖRNYEI, Z. Research methods in applied linguistics: quantitative, qualitative and mixed methodologies. Oxford: Oxford University Press, 2007.

DUTRA, E. O. (2015). Os efeitos da Instrução com Foco na Forma na aprendizagem dos clíticos de $3^{a}$-pessoas do espanhol por universitários brasileiros. 300f. Tese (Doutorado em Linguística Aplicada) - Programa de Pós-Graduação em Linguística Aplicada, Universidade do Vale dos Sinos, São Leopoldo, 2015.

DUTRA, E. O. A interação entre o tratamento instrucional e a prontidão de desenvolvimento de aprendizes no processo de aquisição dos clíticos de terceiras pessoas do espanhol.DOMÍNIOSDELINGU@GEM, v. 13, p. 211, 2019a.

DUTRA, E. O. A aprendizagem dos clíticos de terceira pessoa do espanhol por universitários brasileiros: o efeito e a durabilidade da intervenção instrucional. Revista Brasileira de Linguística Aplicada, v. 19, p. 477-498, 2019 b. 
REVISTA X, Curitiba, volume 14, n.6,p. 178-202, 2019.

ELLIS, R. Introduction: Investigating form-focused instruction. Language Learning, S1: v. 1, p. 1-46, 2001. Disponível em: https://onlinelibrary.wiley.com/doi/abs /10.1111/j.1467-1770.2001.tb00013.x. Acesso em: 05 mai. 2018.

ELLIS, R. La adquisición de segundas lenguas en un contexto de enseñanza. Análisis de las investigaciones existentes. Departamento Técnico del Ministerio de Educación de Nueva Zelanda: Wellington, 2005. Disponível em: http://www.mecd.gob.es/dctm /redele/Material-RedEle/Biblioteca/2006_BV_05/2006_BV_05_04Ellis.pdf?document $\mathrm{Id}=0901 \mathrm{e} 72 \mathrm{~b} 80 \mathrm{e} 3 \mathrm{a} 029$. Acesso em: 20 set. 2018.

ELLIS, R. Measuring Implicit and Explicit Knowledge of a Second Language: A Psychometric Study. Studies in Second Language Acquisition, n. 27, 2005. Disponível em: http://cambridge.org/core/journals/studies-in-second-language-acquisition/article/ measuring-implicit-and-explicit-knowledge-of-a-second-language-a-psychometric-study /0708428E45AEA716C06E47ED37785D4E. Acesso em: 20 set. 2018.

LARSEN-FREEMAN, D.; LONG, M. Introdución al Estudio de la Adquisición de Segundas Lenguas. Madrid: Gredos, 2004.

LOOSE, R. E. O papel da Instrução Explícita na Aquisição/Aprendizagem de Estruturas do Espanhol por falantes do Português. 187f. Dissertação (Mestrado em Letras) - Universidade Católica de Pelotas, Pelotas, 2006.

MORAES, G. B. A aprendizagem do presente do subjuntivo do espanhol por alunos brasileiros: um estudo com foco na forma. 168f. Tese (Doutorado em Linguística Aplicada) - Universidade do Vale do Rio dos Sinos, São Leopoldo, 2014.

MORAES, G. B. Um estudo com foco na foma (IFF): o presente do subjuntivo em espanhol. Revista Brasileira de Linguística Aplicada (Impresso), v. 16, p. 51-80, 2016.

MORAES, G. B; DUTRA, E. O.; SIMIONI, T. A aprendizagem do presente do subjuntivo do espanhol em orações temporais com cuando por universitários brasileiros: os efeitos da intervenção instrucional na redução de transferência linguística. Trabalhos em Linguística Aplicada, v. 57, p. 467-491, 2018.

NORRIS, J.; ORTEGA, L. Efectiveness of L2 instruction: A research synthesis and quantitative meta-analysis. Language Learning, v. 50, p. 417-528, 2000. Disponível em: https://onlinelibrary.wiley.com/doi/abs/10.1111/0023-8333.00136. Acesso em: 15 jan. 2017.

ORTIZ-PREUSS, E. A interface entre os conhecimentos implícito e explícito: um estudo baseado no aspecto verbal. 165f. Dissertação (Mestrado em Letras) Universidade Católica de Pelotas, Pelotas, 2005.

ORTIZ-PREUSS, E. Ensino do verbo gustar em espanhol para brasileiros: intervenção pedagógica baseada na instrução de processamento. LETRÔNICA, v. 10, p. 789-804, 2017. Disponível em: http://revistaseletronicas.pucrs.br/ojs/index.php/letronica /article/view/26410. Acesso em: 10 mai. 2019. 
REVISTA X, Curitiba, volume 14, n.6,p. 178-202, 2019.

PAIVA, V. L. Manual de Pesquisa em Estudos Linguísticos. São Paulo: Parábola, 2019. v. $1.157 \mathrm{p}$.

SANTORO, M. Morphological Variability in Interlanguage Grammars: New Evidence From the Acquisition of Gender and Number in Italian Determiner Phrases and Direct Object Pronouns. Canadian Journal of Applied Linguistics / Revue canadienne de linguistique appliquee. v. 15, n. 1, p. 167-189, 2012.

SHINTANI, N.; LI, S.; ELLIS, R. Comprehension-Based Versus Production-Based Grammar Instruction: A Meta-Analysis of Comparative Studies. Language Learning, v. 63, n. 2, 2013, p. 296-329. Disponível em: https://onlinelibrary.wiley.com/doi/abs /10.1111/lang.12001. Acesso em: 20 set. 2018.

SPADA, N. Form-focused instruction and second language acquisition: A review of classroom and laboraty research. Language Teaching. v. 30, p. 73-87, 1997a. Disponível em: https://www.cambridge.org/core/journals/language-teaching/article/ formfocussed-instruction-and-second-language-acquisition-a-review-of-classroom-andlaboratory-research/9E8079880B5DDA83C9ECC8F2E74D28B1. Acesso em: 10 set. 2018.

SPADA, N.; LIGHTBOWN, P. Question of Timely Enhancement. Artigo apresentado na American Association for Applied Linguistics (AAAL), Orlando, Florida, mar., 1997b. Acesso em: 20 set. 2018.

SPADA, N. Beyond form-focused instruction: Reflections on past, present and future research. Language Teaching, v. 44, p. 225-236, 2010. Disponível em: https://www.cambridge.org/core/journals/language-teaching/article/beyond-form focused-instruction-reflections-on-past-present-andfutureresearch/EAA4A93BF1AB5241ECC85B504C97942D. Acesso em: 10 set. 2018.

SPADA, N.; LIGHTBOWN, P. Form-focused instruction: isolated or integrated? TESOL Quartely, v. 42, n. 2, p. 181-207, 2008. Disponível em: https://onlinelibrary.wiley.com/doi/abs/10.1002/j.1545-7249.2008.tb00115.x. Acesso em: 10 set. 2018.

SPADA, N.; TOMITA, Y. Interactions between type of instruction and type of language feature: A meta-analysis. Language Learning, v. 60, n. 2, p. 1-46, 2010. Disponível em: https://onlinelibrary.wiley.com/doi/abs/10.1111/j.1467-9922.2010.00562.x. Acesso em: 10 set. 2018.

SPADA, N.; JESSOP, L.; SUZUKI, W.; TOMITA, Y. Isolated and integrated formfocused instruction: Effects on different types of L2 knowledge. Language Teaching Research, p. 1-21, 2014. Disponível em: https://journals.sagepub.com/doi/abs /10.1177/1362168813519883. Acesso em: 30 set. 2018.

SWAIN, M. Three functions of output in second language learning. In: COOK, Guy; SEIDLHOFER, Barbara. (Orgs.). Principles and practice in applied linguistics: Studies in honour of H. G. Widdowson. Oxford: Oxford University Press, 1995, p. 125-144. 
REVISTA X, Curitiba, volume 14, n.6,p. 178-202, 2019.

SWAIN, M. Atención a la forma a través de la reflexión consciente. In: DOUGHTY, Catherine; WILlIAMS, Jessica. (Orgs.) Atención a la Forma en la Adquisición de Segundas Lenguas en el aula. Tradução e edição espanhola. Madri: Editorial Edinumen, 1998. 
REVISTA X, Curitiba, volume 14, n.6,p. 178-202, 2019.

\section{APÊNDICE A - TAREFA DE PREENCHIMENTO DE LACUNAS - NÃO DIGITAL}

\section{Completa los huecos.}

a) Yo (tener) veinte años.

b) Me casaré cuando (encontrar) el amor de mi vida.

c) Mis padres serán felices aunque no (tener-yo) hijos.

d) Mis compañeros de clase (estar) en el aula 23.

e) Vamos a donde mi madre (querer).

f) Cuando (estar) en Barcelona, visitaré la Catedral.

g) Mis primos (leer) el periódico todos los días.

h) Seré feliz aunque no (parecer).

i) Mi tía busca un trabajo donde (poder) mostrar su calificación.

j) Contará la verdad cuando (saber) la noticia.

k) Hoy (ser) 20 de abril.

1) Aunque (ponerse) el vestido negro, no me quedará más delgada.

m) Vendrá mi hermano cuando (irse).

n) $\quad$ i madre (comprar) pan todas las mañanas. 


\section{APÊNDICE B - TAREFA DE MÚLTIPLA ESCOLHA - DIGITAL PLATAFORMA EDMODO}

En cada caso, elige y escribe la opción que mejor completa cada frase.

1) Cuando mi hermano la chaqueta, me la prestará.
a) Comprar
b) compre
c) compró

2) Yo siempre temprano al trabajo.
a) Llego
b) llegar
c) llegan

3) Mi hermano no vendrá aunque bien.
a) estuvier
b) esté
c) está

4) Cuando entradas para el espectáculo, las compraré.
a) Haber
b) hay
c) haya

5) Vamos a donde él
a) consiga
b) consigue
c) conseguir

6) Hoy yo

un vestido nuevo.
a) Compré
b) compró
c) compraba

7) Aunque me ir, no iré.
a) Dejan
b) dejaren
c) dejen

8) Mis primas buscan una tienda donde un empleo.
a) Logren
b) logran
c) lograr

9) Mi padre siempre tarde en casa.
a) Llega
b) llegan
c) llegue

10) Te invitaré a tomar algo cuando del cine.
a) Salimos
b) salgamos
c) salirmos 
REVISTA X, Curitiba, volume 14, n.6,p. 178-202, 2019.

\section{APÊNDICE C - TAREFA DE DESCRIÇÃO DE IMAGEM - NÃO DIGITAL}

Describe las siguientes imágenes de manera que puedas contestar a las preguntas.

a) ¿Cuándo viajará?

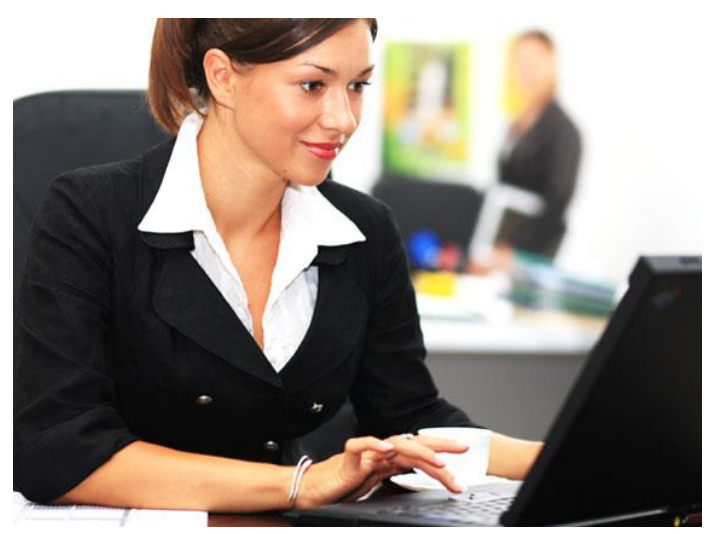

¿Volverás al trabajo?

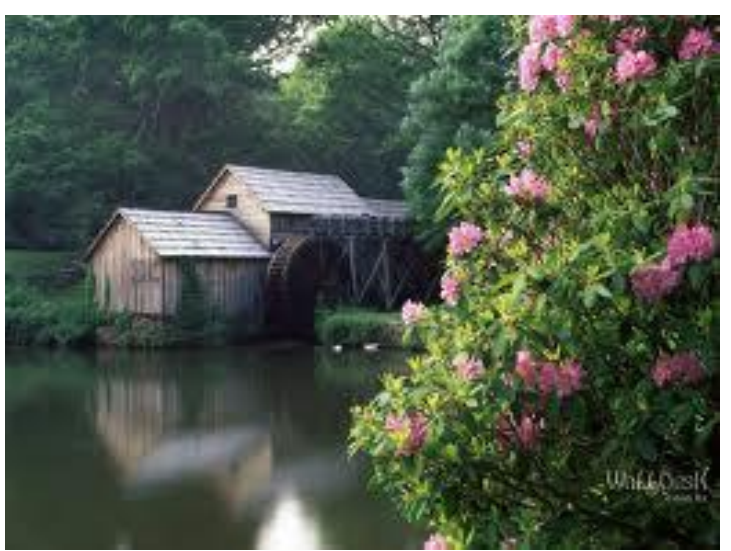


REVISTA X, Curitiba, volume 14, n.6,p. 178-202, 2019.

\section{APÊNDICE D - TAREFA DE CRIAÇÃO DE UMA HISTÓRIA - DIGITAL PLATAFORMA EDMODO}

Tú trabajas con cartomancía y como todo(a) joven de 20 años de edad tiene mucha curiosidad y deseo de descubrir qué pasará en su vida futura. Así que ese(a) joven decide consultar tu opinión para verificar qué podrá ocurrir dentro de algunos años. Escribe una historia a partir de hipótesis que podrá confirmarse en la vida de ese(a) joven en las siguientes situaciones: ¿Se casará? ¿Tendrá hijos? ¿Será feliz? ¿Tendrá éxito profesional? ¿Se pondrá enfermo(a)? ¿Morirá? 
REVISTA X, Curitiba, volume 14, n.6,p. 178-202, 2019.

\section{APÊNDICE E - TAREFAS DE PERGUNTAS CONTROLADAS - TEAM SPEAK}

Contesta oralmente a las siguientes preguntas utilizando las conjunciones cuando, donde $\mathrm{o}$ aunque en la respuesta

1) ¿Cuándo terminarás el trabajo? Cuando.....

2) ¿Vendrás a mi casa? Iré a tu casa aunque.....

3) ¿Cuándo tú tienes tiempo libre? Cuando.

4) ¿Irá a verme? Iré a verte aunque....

5) ¿Cuándo irás a la fiesta de cumpleaños de Ana? Cuando....

6) ¿Tus padres te dejan ir a mi casa? Aunque......

7) ¿Buscas un trabajo? Sí, busco un trabajo donde.........

8) ¿Cuándo limpiarás tu dormitorio? Cuando....

9) ¿Dónde están tus hermanos? Están donde.

10) ¿Llegará la profesora a la clase? La profesora llegará a la clase aunque....

11) ¿A dónde vamos? Vamos a donde tú......... 